\title{
ТСM \\ Perceptions of the impact of the COVID-19 pandemic on the work of science journalists: global perspectives
}

\section{Luisa Massarani, Luiz Felipe Fernandes Neves, Marta Entradas, Tim Lougheed and Martin W. Bauer}

\begin{abstract}
The article presents the results of a survey of science journalists from six world regions about their work during the COVID-19 pandemic. The responses show perception of increasing workload for most participants. Local scientists and peer-reviewed articles are the main sources.

According to the respondents, scientists have become more available during the pandemic. The use of preprint articles was a frequent practice, but a considerable proportion declared they did not adopt different procedures when reporting them. Most also said they take fake news into account when writing their stories.
\end{abstract}

Keywords

Health communication; Professionalism, professional development and training in science communication; Science and media

DOI

https://doi.org/10.22323/2.20070206

Submitted: 13th September 2021

Accepted: 21st October 2021

Published: 6th December 2021

Introduction

TV reporters wearing masks and remote zoom interviews are just a small visible part of the profound changes imposed on journalism by the COVID-19 pandemic. For an activity that is essentially based on contact with sources of information, the requirement for social isolation is a considerable obstacle, even though communication technologies meet most of the needs of journalists and have been essential in the major health emergency of this generation.

The difficulties go further. With news taken over by a single subject, many journalists who generally do not cover science topics have had to focus on a complex and specialized issue [IFJ, 2020]. This occurred amid an increasing workload and consequent worsening in pressure and stress [Figaro, 2020; Hoak, 2021], an environment of disinformation [Makri, 2021; Miranda, Fidalgo and Martins, 2021; Perreault and Perreault, 2021; Wardle and Derakhshan, 2017], and the dynamics of science itself, which needed to accelerate its pace to tackle a new disease. Scientific data needed to be published quickly and there was a significant increase in preprint manuscripts, without peer review, which have been widely 
used since the crisis took global proportions [Fleerackers et al., 2021; Fraser et al., 2020]. On the other hand, the pandemic has sparked great public interest in science issues and its processes [Lasser et al., 2020].

Journalism plays a crucial role in providing reliable information about a disease [Chen and Stoecker, 2020; Goldstein, MacDonald and Guirguis, 2015; Vai et al., 2020], its forms of transmission and prevention, and thus contributes to the public adoption of measures that, in the case of the current pandemic, were the only way to contain the spread of SARS-CoV-2 for nearly a year [Guttman and Lev, 2020; Mello et al., 2021]. These measures obviously also needed to be followed by journalists themselves, who live with the risk of contracting COVID-19 if they cannot work from home [Hoak, 2021].

Studies have been carried out to investigate the situation of journalists in the context of the COVID-19 pandemic [Fernandes, 2021; Figaro, 2020; Hoak, 2021; IFJ, 2020; Miranda, Fidalgo and Martins, 2021; Wollnik, 2021]. This article adds a global perspective to these initiatives by presenting the results of a survey of science journalists from countries in six world regions. The questions focused on the workload, the most used sources and the relationship with them, the use of preprint articles, and the ways to deal with fake news during the pandemic. They are part of the Global Science Journalism Report 2021 [Massarani, Entradas et al., 2021], a survey of science journalists' working conditions and professional practices. With questions related to the COVID-19 pandemic, we aimed to examine the work of journalists at a time of crisis, scientific uncertainty and disinformation.

In the first part of the article, we review other studies that sought to understand the ethos of science journalism, in addition to providing an overview of the theoretical foundations that underlie the specific aspects of journalistic work that we addressed in our survey. Next, we explain the methods used in the survey, their limitations, and the description of the results. Finally, we move on to the discussion of data that reveal the changes and particularities of the work of science journalists at a time of crisis, scientific uncertainty and misinformation.

Understanding the ethos of science journalism
Mapping, monitoring and understanding the ethos of any profession is a challenging task. Journalism is no different. Professionals in this area work in a variety of media outlets, execute many functions and have different working relationships with their employers. The requirement for a university degree in journalism to practice the profession also differs in each country. Furthermore, it is difficult to calculate how much workers affiliated with unions and professional associations represent out of the total number of people working in the area. Therefore, any survey that proposes investigating this activity will face difficulties in estimating the scope and possibilities of generalizing its results.

Since 2004, the Pew Research Center has conducted an annual survey of media industry data and trends in the United States. Although these are comprehensive reports that involve a wide variety of media outlets, their focus is on economic and audience aspects, revealing little from a journalist's point of view. Some reports that include surveys of journalists [Pew Research Center, 2004; Pew Research Center, 2007; Pew Research Center, 2008] indicate some trends: staff cuts; an increase in the number of professionals who believe that journalism is going in the 
wrong direction; journalists divided over a positive and negative view of the state of the profession; financial or economic concerns as the most critical problem facing journalism.

The situation becomes even more difficult to monitor when investigating a specific area of journalism, such as science journalism. In 2009, a survey by Nature collected responses from 493 science journalists in the United States and Canada and found a situation of job cuts and an increase in the workload [Brumfiel, 2009]. One in three participants said they saw staff cuts in their organizations. Fifty-nine percent of journalists also stated an increase in the number of items they work on in a given week in the previous five years.

A survey of science journalists in Latin America reveals important differences with the Northern portion of the continent [Massarani, Amorim and Oca, 2012]. The questionnaire was answered by 275 professionals from countries in this region, and the results revealed that they are more satisfied with their careers and more optimistic about what they do compared to other countries. At least at that moment, one decade ago, the authors affirmed that "the feeling of crisis, observed in the US and Europe, does not seem to exist in this part of the globe" [Massarani, Amorim and Oca, 2012, p. 76].

These examples reveal significant regional asymmetries that reflect the different paths of journalism — and science journalism — around the world. These studies were used to build a survey questionnaire that aimed to map the working conditions, practice and ethos of science journalists across the globe. Data collection took place from 2009 to 2012 and gave rise to the Global Science Journalism Report, published in 2013 [Bauer et al., 2013].

The 2013 report presented results from 953 responses, being considerably higher than the others. Journalists from different countries participated and were gathered in six regions: Asia/Pacific, Europe/Russia, Latin America, Northern Africa and Middle East, Sub-Saharan and Southern Africa, U.S.A. and Canada. In summary, the results pointed to an increase in the production of science and technology-related stories on print, web and radio channels, although many respondents, especially those with more experience in the profession, were concerned about the quality of stories or the decline in investigative reporting. The survey also revealed that in the Global South journalists are younger (more under 35) than in Western regions, and the climate there was very optimistic regarding science journalism.

These studies are needed to monitor the impacts of social, economic and technological changes in journalism. For example, it is noted that, with the growth and consolidation of online journalism, issues related to the internet have become part of these surveys [Bauer et al., 2013; Pew Research Center, 2008]. In relation to science journalism, it is possible to observe how the internet is seen as an ally by professionals [Dunwoody, 2014], although this does not necessarily mean that there is a view that it will end traditional forms of journalism, such as the print media.

Due to the magnitude of its impacts, from the simplest aspects of daily life to major global health, social and economic issues, the COVID-19 pandemic is undoubtedly another topic that should be considered in any survey that aims to map and 
monitor a particular professional practice nowadays. This has been done since the beginning of the pandemic in several countries and regions, addressing different issues. For example, in the United States, Hoak [2021] surveyed 222 journalists to assess the role of organizational support during the pandemic in journalist stress. He noted that greater perceived organizational support was associated with lower levels of stress and higher levels of work commitment. Also in the North American context, Perreault and Perreault [2021] conducted interviews with eight journalists and noted that they discursively placed themselves in a vulnerable position, given that many were experiencing the effects of the health crisis in their own lives.

Miranda and colleagues [2021] analyzed a survey of 890 Portuguese journalists to assess the effects of the state of emergency on practices, routines and ethical precepts. They identified a scenario of depersonalization in the interaction with sources, domiciliation of work, alienation from the professional community and an additional concern with the accuracy of information. The research context is similar to that of the survey with 557 communication professionals in Brazil [Figaro, 2020], which reached the following results: there was an increase in the workload; professionals were concerned with salary reduction; and few companies provided resources for them to work from home.

However, as far as we know, this is the first survey that aims to look at the issue globally.

\section{Background}

The questions we addressed to science journalists in our survey were based on three main aspects that have been widely addressed in scholarly literature: the journalism profession, the relationship with the sources, and the communication of uncertainty (in our case, we approached the use of preprints as a source of information, and ways to deal with fake news).

Regarding the first point, some authors have been highlighting a perception of exhaustion in the business model of traditional media outlets, which since the beginning of the century have suffered the consequences of the loss of advertisers and readers [Brumfiel, 2009; Dunwoody, 2014; Schäfer, 2017]. For journalists, this scenario represents pressure on the working conditions, the quality of reportage and the job security.

Schäfer [2017] highlights that science news coverage was affected by three interconnected factors: the growing crisis of legacy media, the rise of online and social media, and the increasing volume and plurality of public communication about many issues, including science. Consequently, science journalists, while using different means of publicizing their work, face pressures for productivity. Surveys show that the workload has grown and that journalists are doing more and different types of reporting, including content for blogs, web stories and podcasts [Brumfiel, 2009].

As for the relationship with the sources, Schäfer [2011] notes that, amidst the large amount of scientific information produced each year, science journalists traditionally draw on a small number of influential scientific journals and generally exhibit a strong dependence on sources. However, this relationship is subject to the conflicts generated by the meeting of two distinct worlds. 
Peters [1995] uses the concepts of cultural difference and intercultural communication to analyze the tension in the interaction between scientific experts and journalists in risk communication. According to the author, cultural differences arise from at least three areas: difficulties in transmitting "meaning" increase as cultural differences increase; group stereotypes as part of the respective cultures may cause prejudices and initial attitudes; and different conventions, norms and roles are confronted and may cause a mismatch of expectations.

One of the differences in journalistic culture is the sense of urgency and novelty, which often leads to reducing science to its practical results and the detachment of its processes and methods. As Dunwoody [2014] notes, science journalism, like other types of journalism, seeks to tie stories to "traditional news pegs" to engage audience attention. This is a particularly sensitive issue at a time when it was necessary to quickly disseminate information about a new disease (often in the form of preprint articles) and in an arena of conflict with the spread of fake news.

Regarding the preliminary dissemination of scientific articles, before peer review, the concern is to balance the need to circulate information that can help fight a disease, guaranteeing that all methodological and ethical procedures were duly respected [Johansson et al., 2018; Kwon, 2020; Majumder and Mandl, 2020; Vlasschaert, Topf and Hiremath, 2020].

In relation to fake news, one of the concerns is its consequences for public health. The problem is not new, but it intensifies with social media and becomes extremely worrying with the current pandemic. Authors agree that fake news, although to a degree that is not yet well defined, can impact the acceptance and implementation of public policies, reduce adherence to technologies and new therapies, and encourage the inappropriate use of medications [Wang et al., 2019; Bastick, 2021; Greene and Murphy, 2021].

In the case of COVID-19, one of the concerns is with the acceptance of the vaccine. An investigation by the Center for Countering Digital Hate estimates that 147 of the largest English language anti-vaxx social media accounts have gained at least 7.8 million followers since 2019 - an increase of $19 \%$ [CCDH, 2020]. In the United States, the tendency to refuse the vaccine was already causing outbreaks of other diseases, such as measles. Early in the current health crisis, Hotez [2020] predicted that the anti-vaccine movement would grow with COVID-19, fueled with fresh conspiracies and new alliances. According to Gorski [2020], one of the alliances was between the anti-vaccine movement and denier groups, which falsely claimed that COVID-19 was not that serious and criticized the lockdown measures and the use of a mask. In different degrees and moments of the pandemic, science journalists had to deal with denialist discourses from government leaders in their own countries, as in the case of the United States and Brazil [Yamey and Gonsalves, 2020; The Lancet, 2020].

Addressing all these issues in a survey is not a simple task. In the next section, we present the methodology we use to account for the objectives, sample limitations, and results. 
Material and methods

\section{The questionnaire}

The Global Science Journalism Report [Bauer et al., 2013; Massarani, Entradas et al., 2021 ] is a survey aimed to examine working conditions, practice and ethos of science journalism across the globe. The first edition was published in 2013, with responses collected in the previous four years. A follow-up of this report was carried out in 2021, with the addition of specific questions about the work during COVID-19.

It is promoted by SciDev.Net — the Science and Development Network -, the London School of Economics and Casa de Oswaldo Cruz - Oswaldo Cruz Foundation, Brazil. The 2021 report had added new partners: the Brazilian Institute of Public Communication of Science and Technology and ISCTE-Lisbon University Institute, in partnership with the World Federation of Science Journalists. ${ }^{1}$

The questionnaire was constructed based on several surveys [Brumfiel, 2009; Maldidier and Boltanski, 1969; Massarani, Amorim and Oca, 2012; Massarani, Neves and Silva, 2021; McGovern, Smeaton and Hill, 2004; Pew Research Center, 2004; Pew Research Center, 2007; Pew Research Center, 2008]. Its current version has 39 questions, ten of them related to work during COVID-19 - four closed, three mixed (closed + open option) and three open questions. The survey was fielded from February to May 2021, launched on the platform Qualtrics.

We obtained 633 responses from science journalists from 77 countries, grouped into six regions: Asia/Pacific; Europe/Russia; Latin America; Northern Africa and Middle East; Sub-Saharan and Southern Africa; U.S.A. and Canada. Half of the questionnaires were not fully completed, for reasons that we do not know (there were reports of internet connection problems during the pandemic). Therefore, the presentation of the results will always indicate the n-value relative to the number of answers to each question.

\section{Representativity of the sample}

It is important to mention that there is no consensus on the definition of what a science journalist is. Defining it as "reporting about science in the news media" leaves out some particularities of the profession, such as journalists who do not only cover science, freelance workers, and professionals from universities, research institutions and foundations [Bauer et al., 2013]. In such a context, in this study, we defined science journalists as those who self-denominated as science journalists. Our definition is based on the identity that these professionals have about themselves and their profession, which includes objective and subjective factors. Gee [2000] and Jones and McEwen [2000] expand the understanding of a "core identity", personal and immutable, to an identity contextually developed.

Therefore, the participants in this survey are considered science journalists because they identify themselves as such.

Tracing and estimating the number of science journalists in any country is even more difficult than defining a science journalist. It should be said, also, that a

\footnotetext{
${ }^{1}$ The Australian National Centre of Public Awareness of Science (Australia), the Center for Ethics in Science and Journalism (Italy) and SciComm X collaborated with the initiative.
} 
'science journalist' certification does not exist worldwide and there are no available lists of science journalists around the globe. Therefore, it is impossible to define a population of science journalists from which to draw a representative sample of respondents. We rely therefore on a 'haphazard sample' of respondents reached through various internet channels, in part by snowballing.

In this context, statistical sampling procedures with estimates of non-response rates and potential biases are impossible to apply. We were left with using as many channels as possible to distribute the survey, although the suspension of in-person events due to the pandemic has left us with practically only the internet for the dissemination and distribution of the survey. We distributed the invitation for participating in the study through calls from the partners of this initiative, who publicized the survey on their websites, online events and social media, and related networks, collaborators and stakeholders. Figure 1 shows the return of responses with several reminders.

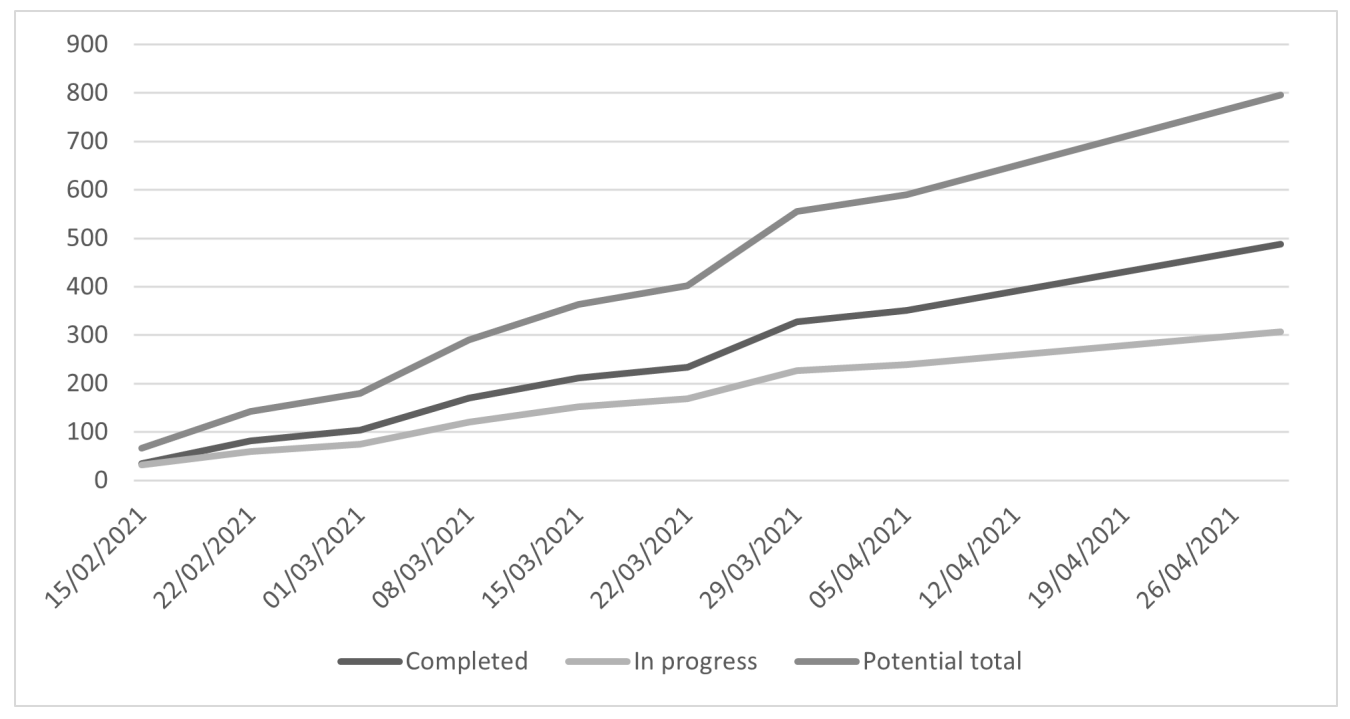

Figure 1. Responses return on Qualtrics.

Therefore, the final sample is unlikely to be representative of the world's science journalists, as we have little information about this group except that it exists. Comparing with the 2009 Nature survey - one of the only surveys done specifically with science journalists in a global perspective - , we obtained greater regional diversity, with more countries in Asia/Pacific and Latin America, in addition to the inclusion of African voices. Other studies carried out with science journalists in the context of a single country reinforce the difficulties of establishing potential biases and different strategies, for example: Kristiansen, Schäfer and Lorencez [2016] approached key organizations and individuals among Swiss science journalists and asked them to distribute the questionnaire, gathering 78 participants; in 2015, the U.S. Society of Professional Journalists and the Union of Concerned Scientists used their networks and obtained 254 responses [Bailin et al., 2015]; Appiah [2010] used the membership list of the Ghana Journalists Association (at the time, with more than 1,000 members) and managed to apply the survey with 151 science journalists; in the U.K., Williams and Clifford [2009] generated a database of 97 national journalists working in the field of science, health, environment and technology and got responses from 42 of them. 
Therefore, the present results are non-responsive to the state of affairs and the situation of science journalism across the world, not least as this study is largely comparable to the similar survey of about ten years ago. Hence, the numbers, especially those related to sociodemographic comparisons, are not the result of dependency calculations between the variables, but only the cross-tabulation from our sample. On the other hand, this survey allows us to guage empirically some important trends in the field of science journalism.

\section{Respondents profile}

Of the 611 participants who provided details of their country, 38\% are from Europe/Russia, 23\% from Latin America, 16\% from Asia/Pacific, 11\% from the U.S.A. and Canada, $8 \%$ from Sub-Saharan and Southern Africa and 5\% from Northern Africa and Middle East (Figure 2). By way of comparison, the Nature survey of 2009 mobilized $42 \%$ of its responses from the U.S.A. and Canada, 50\% from Europe/Russia, 4.5\% from Asia, and 3.5\% from Latin America.

Fifty-four percent of our respondents are women, $44 \%$ are men, and 2\% chose not to respond $(n=618)$. The average age is 44 years old, with the majority $(38 \%)$ in the range of 45 to 64 years $(n=611)$. Northern Africa and Middle East and Latin America have a slightly higher proportion of younger professionals (under 45). On the other hand, the largest proportion of older journalists are in the U.S.A. and Canada.

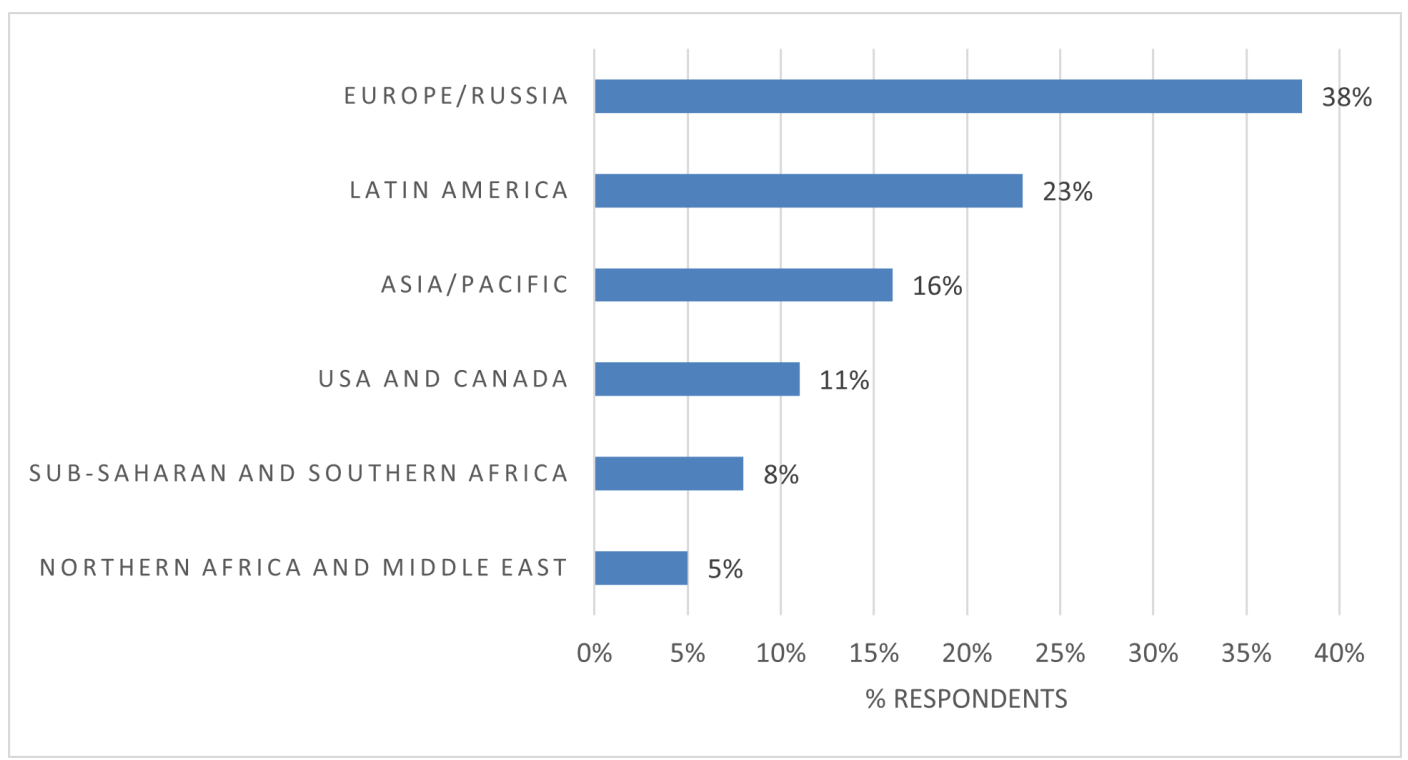

Figure 2. Percentage of respondents from different world regions $(n=611)$.

Almost all participants have a training background, $42 \%$ in science, $37 \%$ in journalism and $17 \%$ in other areas ( $n=617)$. Only $4 \%$ do not have a university degree. Education in science is more common in Europe/Russia and Asia/Pacific; education in journalism is more frequent in Latin America and Sub-Saharan and Southern Africa (Figure 3). Proportionally, there are more women with a university degree in science and journalism (54\% and 59\%, respectively), and more men with a university degree in other fields or without a university degree (51\% and 59\%, respectively). 


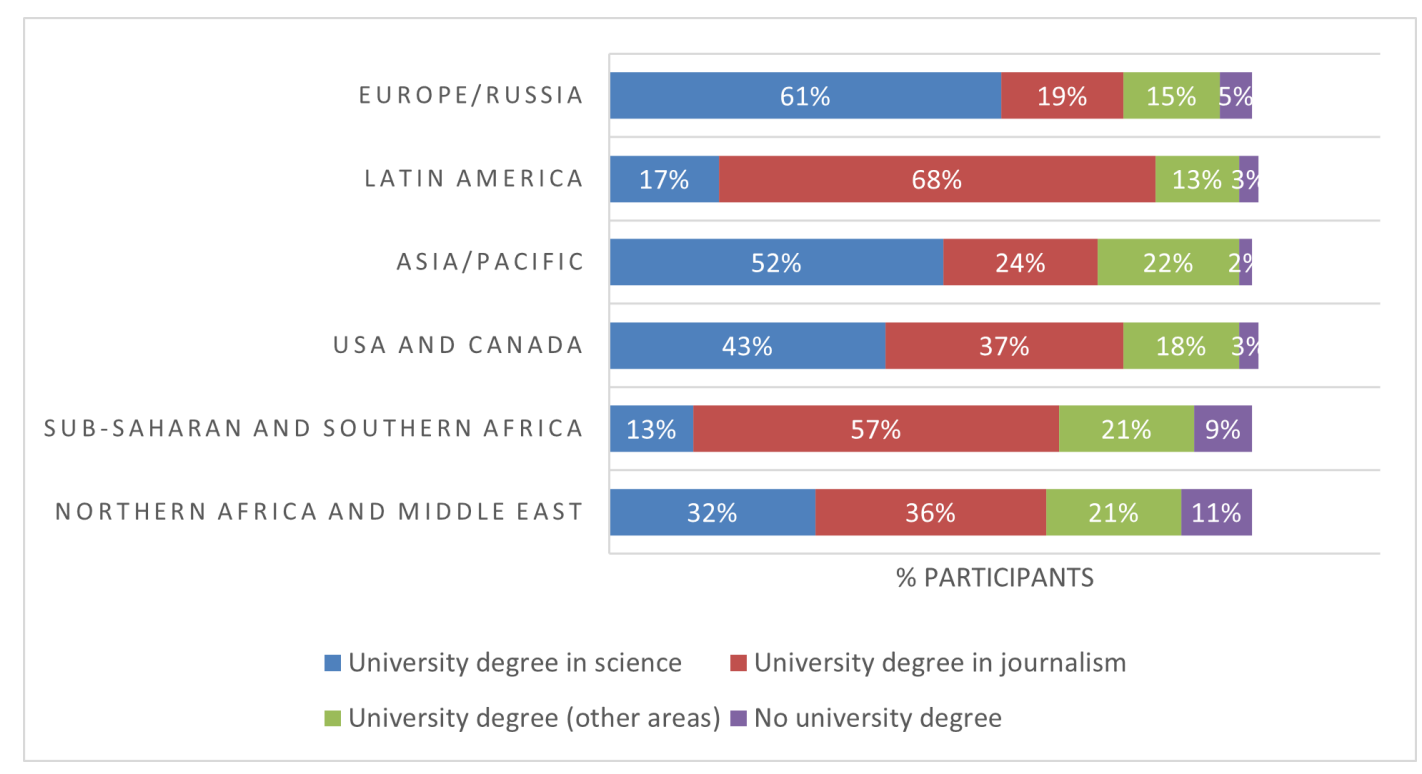

Figure 3. Percentage of respondents by training background.

The sample is also constituted of experienced professionals. Thirty-nine percent have been working with science journalism for more than 15 years, while $15 \%$ have worked for 11 to 15 years, $23 \%$ for six to ten years, and 23\% for less than five years $(n=601)$. The highest proportion of journalists with more years in the field is found in the U.S.A. and Canada. Northern Africa and Middle East have the highest proportion of professionals with less experience (Figure 4). Women predominate in all age groups, except for those with more than 15 years in the profession. In this range, there is a slightly higher proportion of men (52\%). Most professionals (44\%) are full-time staff $(n=600)$. The others are full-time freelance $(28 \%)$, part-time freelance $(15 \%)$, part-time staff $(7 \%)$, and $6 \%$ declared another type of employment position. For $59 \%$ of 609 respondents, science journalism is their main occupation.

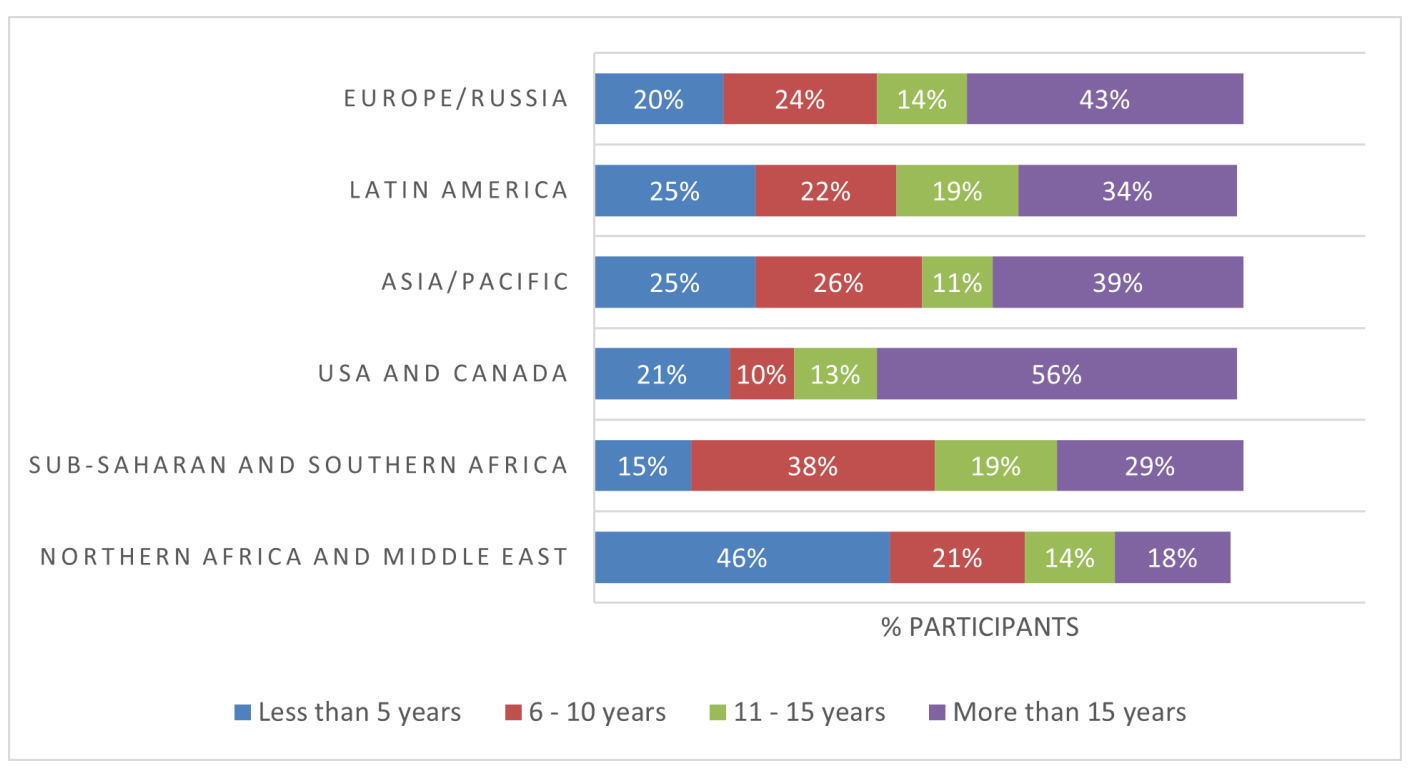

Figure 4. Percentage of participants by working time. 
The COVID-19 pandemic increased the workload of more than half of the science journalists who participated in the survey (Figure 5). Fifty-three percent of them said the number of stories about science topics increased with the pandemic $(n=485)$. For $14 \%$, there was a decrease, and for $33 \%$, the situation has not changed. The highest proportion of respondents reporting an increase in workload was found in Northern Africa and Middle East, where $80 \%$ of respondents in the region chose this option. While the number of professionals who said their workload decreased was low across all regions, it was proportionately higher in Sub-Saharan and Southern Africa (33\%). Europe/Russia recorded the highest proportion of participants who had no change in workload with the pandemic $(46 \%)$.

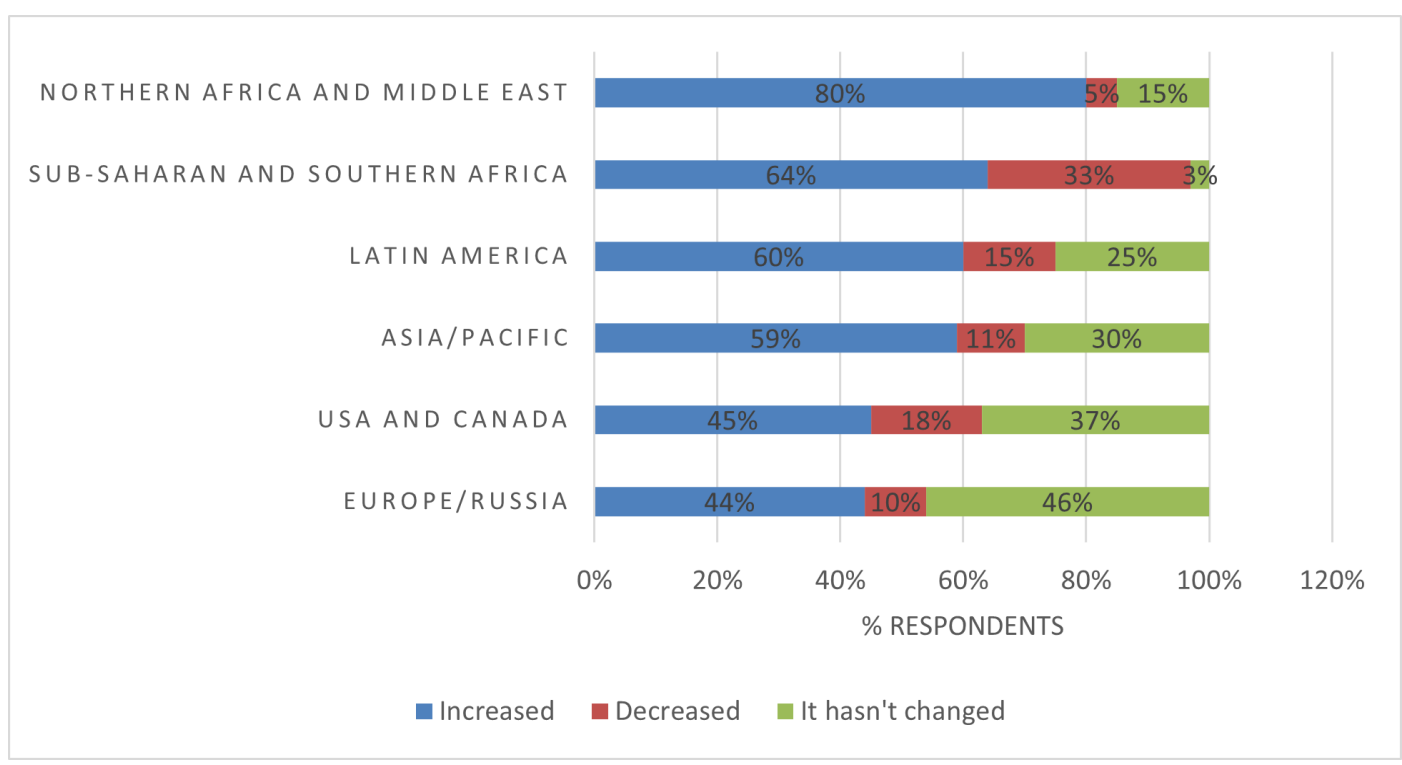

Figure 5. Changing in the number of stories due to COVID-19 pandemic $(n=485)$.

There was little difference between the impact on workload for men and women. Among male professionals, $55 \%$ said that there was an increase in the number of stories, $15 \%$ that there was a decrease, and 30\% that there was no change. The situation is more or less similar among female professionals: $52 \%$ reported an increase, $13 \%$ a decrease, and $35 \%$ reported no change.

In an open-ended question about how the pandemic facilitated or hindered work on covering scientific issues, participants cited a wide range of factors. Among the positive aspects were mentioned: significant public interest in science, greater understanding of science and scientists, more job opportunities, new challenges in the profession and the possibility of exploring other communication resources. The comments below exemplify these aspects:

\footnotetext{
A lot more people have become interested in science, which is great. And a lot more interest inside the newsroom - it will be interesting to see what happens when the pandemic ends (respondent from United States).
}

It's opened up the field enormously I'd say. Mainstream newspapers understand that they need a qualified journalist to cover these issues, but also mainstream journalists have learned enormously about covering science (respondent from United Kingdom). 
The epidemic did not hinder my work in anything. During the epidemic, I used to publish scientific articles on the Internet and I was able to benefit from the lockdown period (respondent from Egypt).

I entered science journalism after the pandemic began! Since the focus of science journalists was completely on the pandemic, I could cover many more stories that were not being covered by the regular science journalists (respondent from India).

Among the negative aspects, journalists mentioned increased workload, exhaustive coverage of a single topic, difficulties in working from home and sharing household chores with work and mobility problems imposed by the lockdown. Some examples:

As I am on home office taking care of little twins as the same time as work, it's have been hard to work as the same way I was before the pandemic (respondent from Brazil).

Being a freelance in a poor country, meant I was hard-pressed to move during lockdown to gather information and also to take pictures (respondent from Uganda).

Due to covid and lockdown, I could not leave Colombia in March 2020 to return to Germany. So I had to create new means of income here in Colombia. Which is, among others, teaching English and technology (respondent from Colombia).

It made it very hard, I had to produce a lot more and most of it was not my choice and was not relevant, a lot of irrational decision from editors. Hard to be the only science journalist, feeling of fighting against windmills (respondent from Switzerland).

\section{Sources and access to sources}

Participants also indicated the main sources used in the science stories related to the new coronavirus (Figure 6). The most frequent choices were scientists from their countries and peer-reviewed scientific articles, both with a frequency of $21 \%$ (in this question, respondents could choose more than one option, so the $\mathrm{n}$ of responses is 1,750). Following are official institutions (such as health ministry and health agency) $(19 \%)$, scientists from other countries $(14 \%)$, doctors $(12 \%)$, and scientific articles that have not been peer-reviewed (10\%). This pattern was roughly similar across regions, except for African and Middle Eastern countries, where official institutions appear first.

For $48 \%$ of participants, with the COVID-19 pandemic, scientists were more easily available to talk to than in normal years $(n=464)$. On the other hand, for $21 \%$ of them, scientists were more difficult to reach and access than usual. For $31 \%$, there was no difference. Only in the U.S.A. and Canada did the proportion of those who said there was no difference surpass the other options. Regarding the scientists' attitudes, the answers were more divided. Thirty-seven percent of respondents consider that the scientist sources were more open and talkative than in previous years $(n=455)$. For $36 \%$, there was no difference. Another $27 \%$ said scientist sources were more cautious when talking to them than in normal years. 


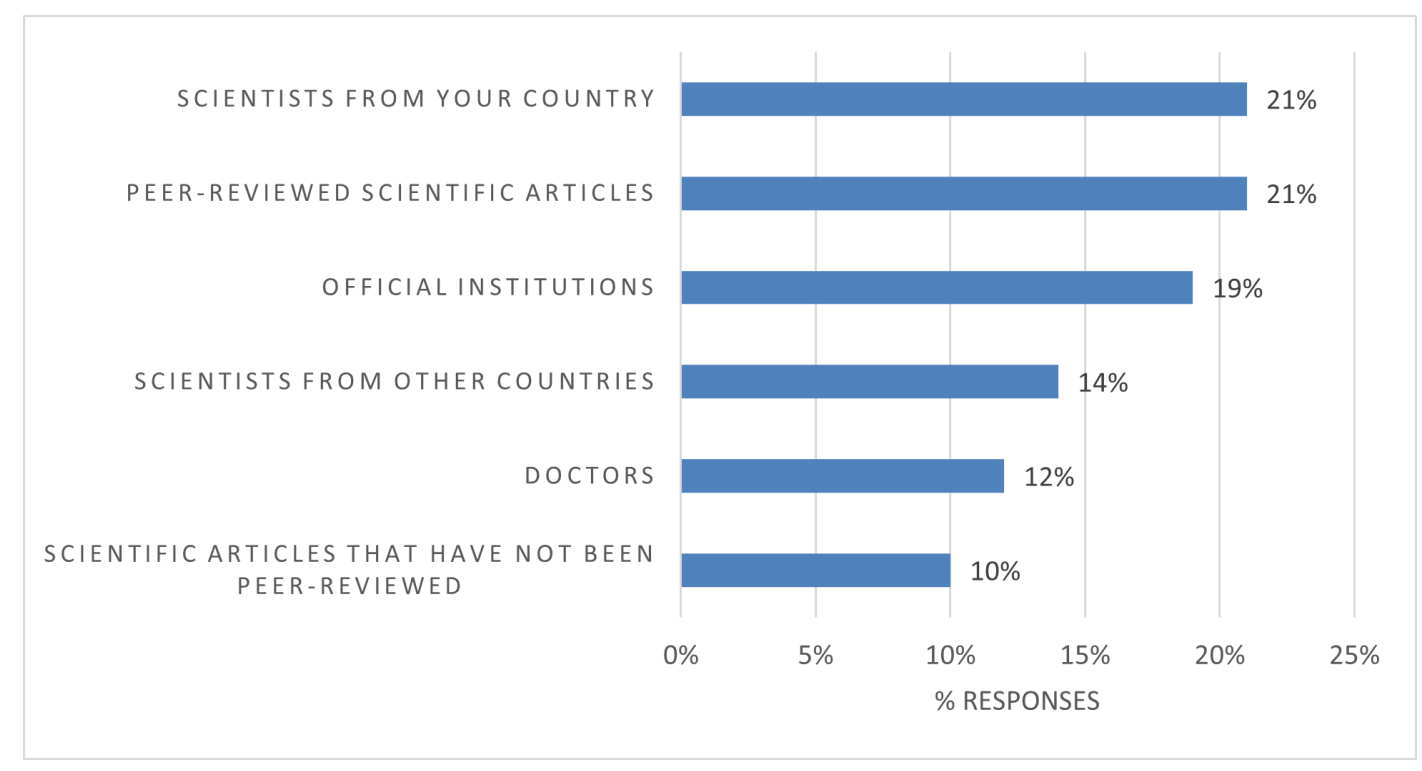

Figure 6. Main sources used in science stories related to COVID-19.

\section{Preprint use and practice change}

More than half of science journalists (55\%) said they used preprint articles in their stories $(n=465)$. This percentage was higher in Asia/Pacific, where $60 \%$ of respondents used this type of study. The situation was reversed in African and Middle Eastern countries, where more than $60 \%$ of participants said they had not used articles without peer review. In this question, journalists were able to say why they did not use preprints. Many responses raise concern that these studies have not yet been evaluated by other scientists, the possibility of not confirming the results, and the need to inform accurately.

We also ask if, when preparing a story based on a preprint, the journalists adopt some different procedures than they usually do when covering science topics (Figure 7). Fifty-nine percent said yes, and $41 \%$ said no $(n=384)$. In Europe/Russia, there is the highest proportion of journalists who adopt different procedures (69\%). In Northern Africa and Middle East, half of journalists said yes, and half said no. In Sub-Saharan and Southern Africa, the proportion of professionals who do not adopt different procedures is much higher: $71 \%$ against $29 \%$ who do.

Asked what these procedures are, many journalists said they try to clarify that the article has not yet been peer-reviewed. Another measure adopted by the journalists is to consult other scientists on the subject of the study. We also asked participants to comment on the increased pace of scientific research. Most answers reveal caution, as can be seen in the following examples:

My experience helped me to be more cautious and avoid embellishing "findings" that might hide commercial advertisements from the pharmaceutical industry or unintentional methodological error by researchers. I think the pandemic has highlighted, both in journalism and in academia, the need to include the concept of uncertainty, despite the global pressure to talk about "outcomes" (respondent from Argentina). 


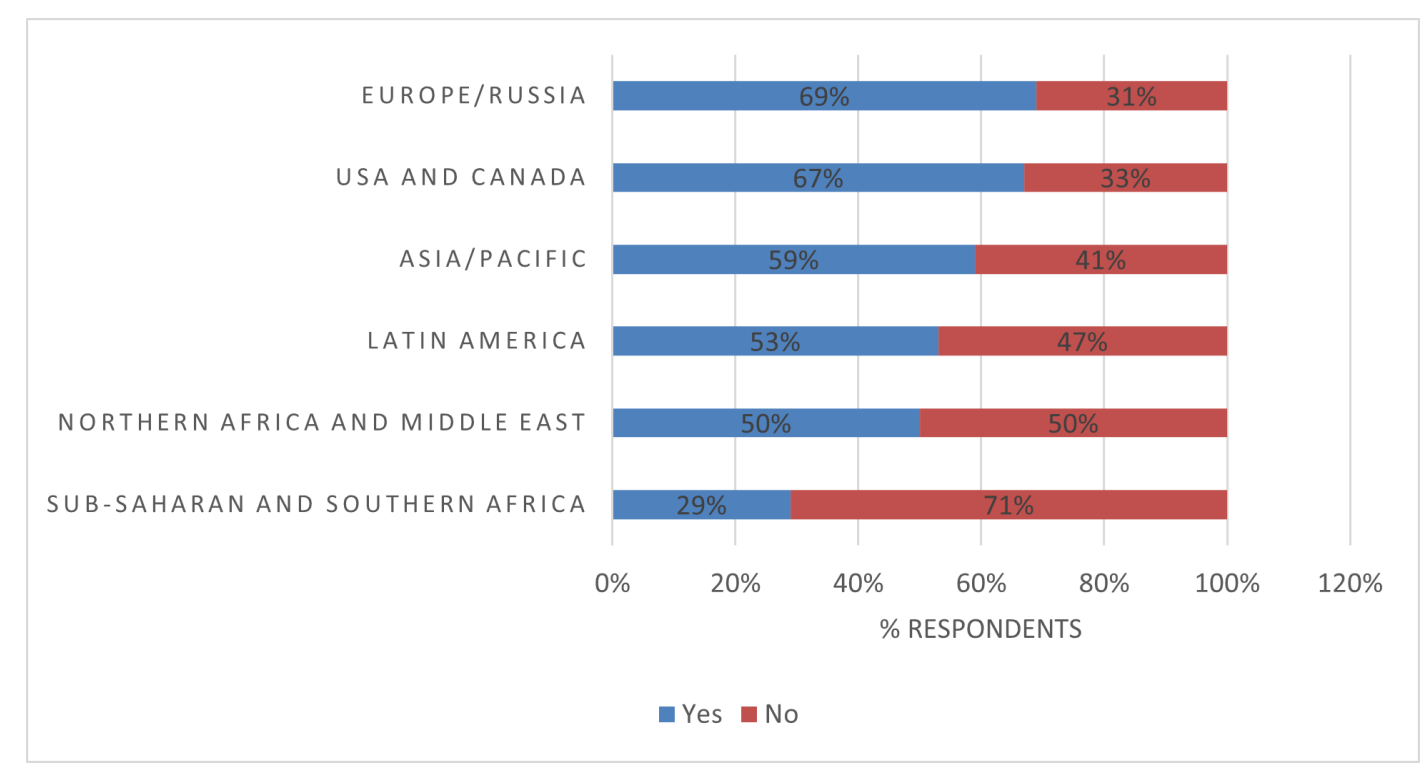

Figure 7. Adoption of different procedures to cover preprint articles $(n=384)$.

I have to always write disclaimers in my stories that the medications are still under development or under emergency use authorization, which is different from those already with marketing authorization of had gone through phase 4 trials (respondent from Philippines).

I search preprint databases for the latest science, but always critically evaluate whether the expertise of the scientist fits with the topic of the preprint. If investigating further, I seek independent comment on the paper from other researchers in the field (respondent from Australia).

\section{Fake news awareness}

Most participants (64\%) take fake news into account when writing their stories $(n=465)$ (Figure 8). In the U.S.A. and Canada, this proportion reaches $85 \%$. A different pattern is verified only in Latin America, where half said yes, and the other half said no. We ask participants to say what they do to check that the information is true. Once again, the procedures involve fact-checking and consulting different sources, such as scientific journals, official institutions and experts. Here are some responses:

We check the information with known and respected scientists on our government board, and consult websites that keep track of fake information (respondent from United States).

Using methods of proper journalism: verification and evaluation of sources, cross checking with multiple reliable sources, checking for conflict of interest, etc (respondent from Jordan).

I check as usual, but I have to devote even more time to explain to my readers the vetting process, and why it is fundamental, since the idea itself of 'fake news' is very simplistic and often fake news appear in the peer-reviewed literature or in press-releases from 'authoritative' institutions (respondent from Italy). 


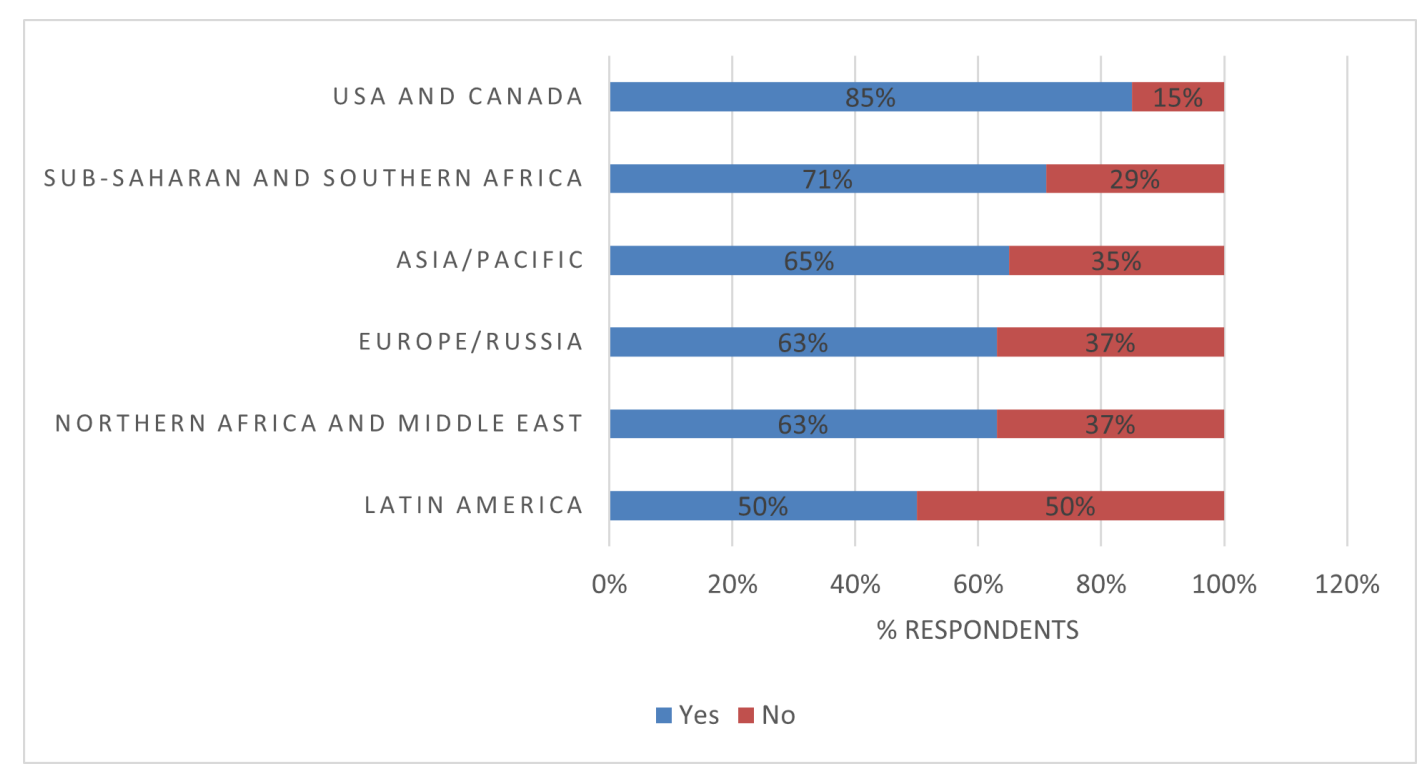

Figure 8. Dealing with fake news $(n=465)$.

Discussion
Even in normal times, the increase in workload year after year is a reality for journalists, as shown by several surveys [Bauer et al., 2013; Brumfiel, 2009; Pew Research Center, 2007; Pew Research Center, 2008]. Our results reveal that the COVID-19 pandemic imposed an additional workload on more than half of science journalists around the world, corroborating the results of the survey by the International Federation of Journalists (IFJ), which found that more than a third of journalists have shifted their focus to covering COVID-19 related stories [IFJ, 2020].

Some view this positively, as this increment has translated into more job opportunities, new challenges and greater consumption of scientific information by the public. On the other hand, many comments make clear the stress caused by the increased workload, especially with the need to reconcile work and social isolation measures. In addition, studies reveal a scenario of little technical infrastructure for work performance away from newsrooms, insecurity with the risk of exposure to the virus, wage losses and precarious employment relationships [Figaro, 2020; Hoak, 2021; IFJ, 2020].

As we have a haphazard sample, we cannot accurately estimate the impact of this workload for men and women. However, it is important to highlight that the COVID-19 pandemic had more severe consequences for women [ILO, 2020]. The United Nations report [2020] lists some of them: lower income and job security, less access to sexual and reproductive health services, increase in unpaid care work, and increase in domestic violence. The IFJ survey also found that, for many female journalists, the pandemic has worsened a situation that was already unfavorable before the health crisis. The survey shows that two thirds of women, as opposed to half of men, have experienced increased anxiety and stress.

Our results also allow us to say that, in general, the COVID-19 pandemic brought journalists and scientists together - the latter considered the main source of information for the stories. For most respondents, scientists were more available and talkative. The fact that this result was different in the U.S.A. and Canada 
(where there is a higher proportion of participants who declared that there was no difference in access to scientists) may be an indication of a particularity verified by Hoak [2021] among journalists in the United States. This survey found that the top stressor for newspaper journalists was finding and reaching sources.

A personal or institutional willingness to facilitate journalists' access to scientific sources can contribute to the transparency of information [Dance, 2018]. For example, the case study by Lasser et al. [2020] reports the experience of the Complexity Science Hub Vienna (CSH), which quickly changed communication from a "science push" to a "policy (and media) pull" scenario. Thus, researchers on the front line were asked to participate in the publication cycle of broad media outlets to a far greater extent than before the crisis.

In this context, we bring the discussion raised by Miranda, Fidalgo and Martins [2021] on the effect of lockdown on changing practices and ways of contact with sources and with the places of events. The survey with Portuguese journalists identified the replacement of more direct and face-to-face formulae by synchronous or asynchronous distance contact models. The authors point out that this replacement is not a new or ephemeral phenomenon, but rather suggests a response to labor reorganization trends, underlining the technological and economic reorganization of the media industry.

In any case, trust in scientific sources is evident in the participants' responses, corroborating the testimonies collected by Makri [2021] with journalists covering COVID-19. This is also evident in our survey questions related to the use of preprint articles. This type of study, which had an exponential increase in the COVID-19 pandemic [Fleerackers et al., 2021; Fraser et al., 2020], was used by just over half of the participants, and we see that seeking validation with other experts is a frequent way to check the information. However, it is noteworthy that a significant part of the sample (41\%) admitted not to adopt different procedures when preparing a story based on a preprint. The fact that this situation has been more frequent in African countries and less frequent in European countries requires further studies in order to relate it to the maturity of science journalism in different regions.

Preprint repositories are not new and have been used primarily in the medical and biological fields for over half a century [Cobb, 2017]. As the peer review process can be lengthy, the practice of publishing versions that other scientists have not yet evaluated is common during health crises, such as the Ebola and Zika outbreaks [Johansson et al., 2018]. In 2015, the World Health Organization (WHO) consulted with stakeholders to develop global standards for sharing data and results during public health emergencies, and some of the most important scientific journals signed a consensus statement encouraging it. Munafò [2016] lists the publication of preprints as one of the ways to increase quality control procedures at each stage of the research, also increasing their reproducibility.

However, the main discussion is on the balance between the need to share scientific data quickly to try to contain a disease and the guarantee of ethical and methodological rigor and the correct interpretation of results [Johansson et al., 2018; Kwon, 2020; Majumder and Mandl, 2020; Vlasschaert, Topf and Hiremath, 2020]. Journalistic principles provide means and tools for the correct verification of 
data, including scientific data, but the fact that four out of ten participants in our survey stated that they do not adopt different procedures is worrying in a context of intense circulation of information and disinformation [Wardle and Derakhshan, 2017; WHO, 2020]. As of mid-July 2021, two of the major preprint repositories (bioRxiv and medRxiv) had published more than 17,500 articles on the new SARS-CoV-2 coronavirus.

A more significant concern of our survey participants was verified in relation to fake news, another problem prior to the pandemic and which became even more evident. Once again, the slightly different situation in Latin America, where half of the respondents said they did not take fake news into account when writing their stories, should be further analyzed. But overall, our results confirm recent studies. The survey carried out by Miranda, Fidalgo and Martins [2021] with Portuguese journalists shows that the concern with the accuracy of information is the most mentioned among the ten items proposed, in all categories, age groups and levels of remuneration. In interviews conducted with journalists, Perreault and Perreault [2021] found that misinformation is one of the reasons journalists constructed their relationship with information during the pandemic as innately problematic.

When commenting on how they deal with fake news, journalists point to the importance of fact-checking, which has played an essential role in the current pandemic [Massarani, Brotas et al., 2021; Patatt and Rocha, 2020]. Perreault and Perreault [2021] note that journalists usually disclose their verification process to the public to connect readers with sources that will establish accuracy patterns through transparent business practices. According to the authors, while journalists have a long-standing concern for the process of verification, during the early phases of the COVID-19 crisis, the metajournalistic discourse emphasized concerns regarding credibility and news validity in discussing journalistic work with other entities.

Disinformation in health-related issues has an aggravating factor, as it can affect the perception of risk and the public's behavior [Chen and Stoecker, 2020; Goldstein, MacDonald and Guirguis, 2015; Vai et al., 2020]. This is an even more complex environment due to the strong role of social media in disseminating false information, which also demands the journalists' attention.

Final considerations
In this article, we presented the results of a survey that aimed to investigate the impacts of the COVID-19 pandemic on the work of science journalists around the world. Participants from six world regions answered questions related to workload, the most used sources and the relationship with them, the use of preprint articles, and ways to deal with fake news. In the wake of other studies on journalism in times of pandemic [Fernandes, 2021; Figaro, 2020; Hoak, 2021; IFJ, 2020; Lasser et al., 2020], we can conclude that the health crisis of enormous proportions imposed - and continues to impose - drastic changes on science journalism, intensifying challenges and dilemmas prior to the pandemic [Miranda, Fidalgo and Martins, 2021; Perreault and Perreault, 2021].

However, these changes need to be considered from different aspects. For example, the intense workload is a consequence of the greater circulation and consumption of scientific information, which is positive, but overworked professionals are 
producing them in an increasingly lean labor market. Scientists and scientific articles are the main sources for journalists, but to what extent are these professionals prepared and qualified to deal with specialized coverage? The same can be questioned in relation to the significant portion of participants who admitted not adopting different procedures when reporting a study that was not peer-reviewed.

From a positive perspective, perhaps the need to report a complex scientific subject contributes to the professionalization of science journalism, which has already been verified in recent years [Hayden and Hayden, 2018]. Furthermore, the results indicate that there have also been changes in science, with greater availability of scientists. In this sense, the pandemic may have increased mutual understanding between journalists and scientists, since, according to Hayden and Hayden [2018, p. 2], these are parallel pursuits: "Both are practices of inquiry that take the pursuit of verifiable truth as their highest calling. Both are built on the individual curiosity and dedication of practitioners pursuing the public good, and both have well-developed traditions and professional structures that support this calling". The extent of these changes and their duration in time remain unknown and need to be monitored systematically.

Concerning the regional differences identified in this survey, they point to the possibility of a more considerable impact of the pandemic in African countries, whose journalists also revealed a more pronounced dependence on sources from official institutions. The answers seem to indicate science journalism as a more consolidated practice in North American and European countries. This is not a surprising result, but our survey shows evidence of impact of such consolidation in practices during the pandemic: among the North American group, there is a significant concern with fake news; among European journalists, we observed greater care when dealing with studies that have not yet been peer-reviewed. However, it is necessary to take into account the sample limitations, so that the present results can be used for further investigations.

Almost two years after the first cases of a disease caused by a new coronavirus, in China, the pandemic, although far from being fully controlled, appears to be fading worldwide, with some countries returning to apparent normality. However, the stagnation of vaccination in the United States and the consequent increase in cases of COVID-19 are just one of the examples that it is necessary to remain vigilant, including in the ways to deal with uncertainty and misinformation. Our survey gives some clues that, although there is an exhaustive competition with information without scientific evidence, false news, and allegations, the current situation has also been a good opportunity to explain to the public the processes of science [Lasser et al., 2020], its fallibility, and that, above everything, that science is not a finished enterprise [Latour, 1987]. Therefore, it needs to be communicated "with an irreducible level of uncertainty" [Fernandes, 2021, p. 4]. We expect that future research can demonstrate whether the evidence we found in our study goes beyond the pandemic, which could mean that the crisis has translated into an opportunity to practice better quality science journalism. 
Acknowledgments LM thanks the National Council for Scientific and Technological Development (CNPq) for the Productivity Fellowship and the Carlos Chagas Filho Foundation for Research Support of the State of Rio de Janeiro for the Fellowship Our State Scientist.

\section{References}

Appiah, B. (2010). 'Science journalism in Ghana: A study of journalists who cover science'. Master's thesis. Texas A\&M University, U.S.A. URL: http://oaktrust . library . tamu . edu/handle/1969.1/ETD-TAMU-2010-12-8737?show=full.

Bailin, D., Carlson, C. S., Halpern, M., Huertas, A. and Kothari, Y. (2015). Mediated Access: Transparency Barriers for Journalists' Access to Scientists and Scientific Information at Government Agencies. Tech. rep. U.S.A.: Center for Science and Democracy at the Union of Concerned Scientists. URL: http: //www. jstor.org/stable/resrep17256.

Bastick, Z. (2021). 'Would you notice if fake news changed your behavior? An experiment on the unconscious effects of disinformation'. Computers in Human Behavior 116, p. 106633. https://doi.org/10.1016/j.chb.2020.106633.

Bauer, M. W., Howard, S., Romo Ramos, Y. J., Massarani, L. and Amorim, L. (2013). Global science journalism report: working conditions $\mathcal{E}$ practices, professional ethos and future expectations. Our Learning Series. London, U.K.: Science and Development Network.

Brumfiel, G. (2009). 'Science journalism: Supplanting the old media?' Nature 458 (7236), pp. 274-277. https://doi.org/10.1038/458274a.

Center for Countering Digital Hate (CCDH) (2020). The anti-vaxx industry: How Big Tech powers and profits from vaccine misinformation. UK and US. URL: https: //www . counterhate.com/anti-vaxx-industry.

Chen, W. and Stoecker, C. (2020). 'Mass media coverage and influenza vaccine uptake'. Vaccine 38 (2), pp. 271-277. https://doi.org/10.1016/j.vaccine.2019.10.019.

Cobb, M. (2017). 'The prehistory of biology preprints: A forgotten experiment from the 1960s'. PLOS Biology 15 (11), e2003995. https://doi.org/10.1371/journal.pbio. 2003995.

Dance, A. (2018). 'Smile for the camera'. Nature 562 (7725), pp. 153-155. https://doi.org/10.1038/d41586-018-06871-7.

Dunwoody, S. (2014). 'Science journalism: prospects in the digital age'. In: Routledge Handbook of Public Communication of Science and Technology. Ed. by M. Bucchi and B. Trench. 2nd ed. London, U.K. and New York, U.S.A.: Routledge, pp. 27-39. https://doi .org/10.4324/9780203483794.

Fernandes, A. (2021). 'Communicating Corrected Risk Assessments and Uncertainty About COVID-19 in the Post-truth Era'. Frontiers in Communication 6, pp. 1-6. https://doi.org/10.3389/fcomm.2021.646066.

Figaro, R. (2020). Relatório dos resultados da pesquisa: Como trabalham os comunicadores em tempos de pandemia da Covid-19? São Paulo, Brazil: ECA-USP.

Fleerackers, A., Riedlinger, M., Moorhead, L., Ahmed, R. and Alperin, J. P. (2021). 'Communicating Scientific Uncertainty in an Age of COVID-19: An Investigation into the Use of Preprints by Digital Media Outlets'. Health Communication, pp. 1-13. https://doi.org/10.1080/10410236.2020.1864892.

Fraser, N., Brierley, L., Dey, G., Polka, J. K., Pálfy, M., Nanni, F. and Coates, J. A. (2020). 'Preprinting the COVID-19 pandemic'. BioRxiv. https://doi.org/10.1101/2020.05.22.111294.

Gee, J. P. (2000). 'Identity as an Analytic Lens for Research in Education'. Review of Research in Education 25, p. 99. https://doi .org/10.2307/1167322. 
Goldstein, S., MacDonald, N. E. and Guirguis, S. (2015). 'Health communication and vaccine hesitancy'. Vaccine 33 (34), pp. 4212-4214.

https://doi.org/10.1016/j.vaccine.2015.04.042.

Gorski, D. (2020). COVID-19 pandemic deniers and the antivaccine movement: An unholy alliance. URL: https://sciencebasedmedicine .org/covid-19-pandemic -deniers-and-the-antivaccine-movement-an-unholy-alliance/ (visited on 18th October 2021).

Greene, C. M. and Murphy, G. (2021). 'Quantifying the effects of fake news on behavior: Evidence from a study of COVID-19 misinformation'. Journal of Experimental Psychology. https://doi.org/10.1037/xap0000371.

Guttman, N. and Lev, E. (2020). 'Ethical Issues in COVID-19 Communication to Mitigate the Pandemic: Dilemmas and Practical Implications'. Health Communication 36 (1), pp. 116-123. https://doi.org/10.1080/10410236.2020.1847439.

Hayden, T. and Hayden, E. C. (2018). 'Science Journalism's Unlikely Golden Age'. Frontiers in Communication 2, pp. 1-3. https://doi.org/10.3389/f comm.2017.00024.

Hoak, G. (2021). 'Covering COVID: Journalists' Stress and Perceived Organizational Support While Reporting on the Pandemic'. Journalism E Mass Communication Quarterly 98 (3), pp. 854-874. https://doi.org/10.1177/10776990211015105.

Hotez, P. J. (2020). 'COVID19 meets the antivaccine movement'. Microbes and Infection 22 (4-5), pp. 162-164. https://doi.org/10.1016/j.micinf.2020.05.010.

International Federation of Journalists (IFJ) (30th April 2020). Exposed: The crisis facing journalism in the face of Covid-19. URL: https://www . if j . org/media-centr e/news/detail/category/press-releases/article/exposed-the-crisis-fa cing-journalism-in-the-face-of-covid-19.html.

International Labour Organization (ILO) (2020). COVID-19 and the world of work: Impact and policy responses. URL: https://www. ilo.org/wcmsp5/groups/public /---dgreports/---dcomm/documents/briefingnote/wcms_738753.pdf.

Johansson, M. A., Reich, N. G., Meyers, L. A. and Lipsitch, M. (2018). 'Preprints: An underutilized mechanism to accelerate outbreak science'. PLOS Medicine 15 (4), e1002549. https://doi.org/10.1371/journal.pmed.1002549.

Jones, S. R. and McEwen, M. K. (2000). 'A Conceptual Model of Multiple Dimensions of Identity'. Journal of College Student Development 41 (4), pp. 405-414.

Kristiansen, S., Schäfer, M. S. and Lorencez, S. (2016). 'Science journalists in Switzerland: Results from a survey on professional goals, working conditions, and current changes'. Studies in Communication Sciences 16 (2), pp. 132-140. https://doi.org/10.1016/j.scoms.2016.10.004.

Kwon, D. (2020). 'How swamped preprint servers are blocking bad coronavirus research'. Nature 581 (7807), pp. 130-131. https://doi .org/10.1038/d41586-020-01394-6.

Lasser, J., Ahne, V., Heiler, G., Klimek, P., Metzler, H., Reisch, T., Sprenger, M., Thurner, S. and Sorger, J. (2020). 'Complexity, transparency and time pressure: practical insights into science communication in times of crisis'. JCOM 19 (05), N01. https://doi.org/10.22323/2.19050801.

Latour, B. (1987). Science in action: How to follow scientists and engineers through society. Cambridge, MA, U.S.A.: Harvard University Press.

Majumder, M. S. and Mandl, K. D. (2020). 'Early in the epidemic: impact of preprints on global discourse about COVID-19 transmissibility'. Lancet Global Health 8 (5), e627-e630. https://doi .org/10 .1016/s2214-109x(20)30113-3. 
Makri, A. (2021). 'What do journalists say about covering science during the COVID-19 pandemic?' Nature Medicine 27 (1), pp. 17-20.

https://doi.org/10.1038/s41591-020-01207-3.

Maldidier, P. and Boltanski, L. (1969). La vulgarisation scientifique et ses agents. France: Centre de Sociologie Européenne.

Massarani, L., Entradas, M., Neves, L. F. F. and Bauer, M. W. (2021). Global Science Journalism Report: Working conditions and practices, professional ethos and future expectations. London, U.K. URL: https $\% 3 \mathrm{~A} \% 2 \mathrm{~F} \% 2 \mathrm{Fwww}$. scidev . net $\% 2 \mathrm{Fglobal} \% 2 \mathrm{Fw}$ p-content\%2Fuploads\%2FGlobal-Science-Journalism-Report-2021.pdf.

Massarani, L., Amorim, L. and Oca, A. M. de (2012). 'Periodismo científico: reflexiones sobre la práctica en América Latina'. Chasqui 120, pp. 73-77. URL: https://revistachasqui .org/index.php/chasqui/article/view/530.

Massarani, L., Brotas, A., Costa, M. C. R. and Neves, L. F. F. (2021). 'Vacinas contra a COVID-19 e o combate à desinformação na cobertura da Folha de S. Paulo'. Fronteiras 23 (2), pp. 29-43. https://doi.org/10.4013/fem.2021.232.03.

Massarani, L., Neves, L. F. F. and Silva, C. M. D. (2021). 'Excesso e alta velocidade das informações científicas'. E-Compós. https://doi .org/10.30962/ec. 2426.

McGovern, P., Smeaton, D. and Hill, S. (2004). 'Bad Jobs in Britain'. Work and Occupations 31 (2), pp. 225-249. https://doi.org/10.1177/0730888404263900.

Mello, V. M., Eller, C. M., Salvio, A. L., Nascimento, F. F., Figueiredo, C. M., Silva, E. S. R. F., Sousa, P. S. F., Costa, P. F., Paiva, A. A. P., Mares-Guias, M. A. M. M., Lemos, E. R. S. and Horta, M. A. P. (2021). 'Effectiveness of Face Masks in Blocking the Transmission of SARS-CoV-2: a Preliminary Evaluation of Masks Used by SARS-CoV-2-Infected Individuals'. MedRxiv. https://doi.org/10.1101/2021.06.20.21259167.

Miranda, J., Fidalgo, J. and Martins, P. (2021). 'Jornalistas em Tempo de Pandemia: Novas Rotinas Profissionais, Novos Desafios Éticos'. Comunicação e Sociedade 39, pp. 287-307. https://doi .org/10.17231/comsoc.39(2021). 3176.

Munafò, M. (2016). 'Open science and research reproducibility'. ecancermedicalscience 10. https://doi.org/10.3332/ecancer. 2016. ed56.

Patatt, C. and Rocha, F. (2020). As Fake News e o Coronavírus: uma Análise dos Portais mais Acessados de Brasil e Portugal. Ed. by H. M. G. Oliveira and S. Gadini. Aveiro, Portugal: Ria Editorial, pp. 34-62.

Perreault, M. F. and Perreault, G. P. (2021). 'Journalists on COVID-19 Journalism: Communication Ecology of Pandemic Reporting'. American Behavioral Scientist 65 (7), pp. 976-991. https : //doi.org/10.1177/0002764221992813.

Peters, H. P. (1995). 'The interaction of journalists and scientific experts: co-operation and conflict between two professional cultures'. Media, Culture $\mathcal{E}$ Society 17, pp. 31-48.

Pew Research Center (2004). The State of the News Media. URL: https://www . pewresearch.org/wp-content/uploads/sites/8/2017/05 /State-of-the-News-Media-Report-2004-FINAL.pdf.

- (2007). The State of the News Media.

URL: https://www . pewresearch.org/wp-content/uploads/sites/8/2017/05 /State-of-the-News-Media-Report-2007-FINAL .pdf.

- (2008). The Web: Alarming, Appealing and a Challenge to Journalistic Values. The Pew Research Center. URL: https: //www . pewresearch .org/wp-content/uploads /sites/8/2017/05/State-of-the-News-Media-Report-2008-FINAL .pdf.

Schäfer, M. S. (2011). 'Sources, Characteristics and Effects of Mass Media Communication on Science: A Review of the Literature, Current Trends and Areas for Future Research'. Sociology Compass 5 (6), pp. 399-412. https://doi.org/10.1111/j.1751-9020.2011.00373.x. 
Schäfer, M. S. (2017). ‘How changing media structures are affecting science news coverage'. In: The Oxford handbook of the science of science communication. Ed. by K. Hall Jamieson, D. M. Kahan and D. A. Scheufele. Oxford, U.K.: Oxford University Press, pp. 51-59. https://doi.org/10.1093/oxfordhb/9780190497620.001.0001.

The Lancet (2020). 'COVID-19 in Brazil: "so what?"' The Lancet 395 (10235), p. 1461. https://doi.org/10.1016/s0140-6736(20)31095-3.

United Nations (UN) (2020). Policy Brief: The Impact of COVID-19 on Women. United Nations. URL: https://www . unwomen .org/-/media/headquarters/attachments /sections/library/publications/2020/policy-brief-the-impact-of-covi d-19-on-women-en.pdf.

Vai, B., Cazzetta, S., Ghiglino, D., Parenti, L., Saibene, G., Toti, M., Verga, C., Wykowska, A. and Benedetti, F. (2020). 'Risk Perception and Media in Shaping Protective Behaviors: Insights From the Early Phase of COVID-19 Italian Outbreak'. Frontiers in Psychology 11, pp. 1-8. https://doi.org/10.3389/fpsyg.2020.563426.

Vlasschaert, C., Topf, J. M. and Hiremath, S. (2020). 'Proliferation of Papers and Preprints During the Coronavirus Disease 2019 Pandemic: Progress or Problems With Peer Review?' dvances in Chronic Kidney Disease 27 (5), pp. 418-426. https://doi.org/10.1053/j. ackd.2020.08.003.

Wang, Y., McKee, M., Torbica, A. and Stuckler, D. (2019). 'Systematic Literature Review on the Spread of Health-related Misinformation on Social Media'. Soc. Sci. Med. 240, p. 112552. https://doi.org/10.1016/j. socscimed.2019.112552.

Wardle, C. and Derakhshan, H. (2017). Information disorder: toward an interdisciplinary framework for research and policymaking. Strasbourg, France: Council of Europe. URL: https://rm.coe.int/information-disorder-toward - an-interdisciplinary-framework-for-researc/168076277c.

Williams, A. and Clifford, S. (2009). Mapping the field: Specialist science news journalism in the UK national media. Cardiff, U.K.: Cardiff University.

Wollnik, S. (2021). 'The societal importance of journalistic health reporting on the COVID-19 pandemic in sub-Saharan Africa: Impressions from science and health journalism organizations'. Journal of African Media Studies 13 (2), pp. 139-158. https://doi.org/10.1386/jams_00040_1.

World Health Organization (WHO) (23rd September 2020). Managing the COVID-19 infodemic: Promoting healthy behaviours and mitigating the harm from misinformation and disinformation. URL: https://www.who.int/news/item/23-09-2020-managi ng-the-covid-19-infodemic-promoting-healthy-behaviours-and-mitigati ng-the-harm-from-misinformation-and-disinformation.

Yamey, G. and Gonsalves, G. (2020). 'Donald Trump: a political determinant of covid-19'. BMJ 369, p. m1643. https ://doi .org/10.1136/bmj.m1643.

Luisa Massarani is a Brazilian science communicator who carries out both practical and research activities in the field. She is the coordinator of the National Brazilian Institute of Public Communication of Science and Technology and for Latin American SciDev.Net. She is a researcher at House of Oswaldo Cruz/Fiocruz (Brazil). Fellow Productivity of the National Council for Scientific and Technological Development (CNPq) 1B, Our State Scientist of the Carlos Chagas Filho Foundation for Research Support of the State of Rio de Janeiro (Faperj). She is recipient of the Mercosur Award for Science and Technology (2014), the Brazilian Award for Science Communication (2016) and the Literature Jabuti Award (2017). E-mail: luisa.massarani6@gmail.com. 
Luiz Felipe Fernandes Neves is a PhD candidate in Biosciences and Health at Oswaldo Cruz Foundation (Fiocruz), Brazil. He is a journalist with a master in Communication, and works at the Communication Department of the Federal University of Goiás (UFG), Brazil. The professional activities and academic research include science communication, science journalism, organizational communication, and digital social networks. E-mail: luiz.felipe@ufg.br.

Marta Entradas is Assistant Professor at ISCTE-University Institute of Lisbon, and visiting fellow at London School of Economics (LSE). She is the Principal Investigator (PI) for the international projects 'MORE-PE: MObilisation of REsources for Public Engagement with science' and OPEN: Organisational Public Engagement' ongoing in countries in Europe, Asia and the Americas. She was Marie Curie Fellow at LSE (2016-18) and Fulbright Scholar at Cornell University (2015-16). Her current research focuses on institutional communication of science with society. E-mail: marta.entradas@gmail.com.

Tim Lougheed is the executive director of the World Conference of Science Journalists. He began his career with the Sault Star and the Windsor Star, subsequently working as a science writer for Queen's University in Kingston. Based in Ontario, Canada, he has been a freelance science, technology, and medicine writer since 1991, producing articles that have appeared in Canadian Geographic, University Affairs, Canadian Medical Association Journal, New Scientist, Ensia, Nautilus, Environmental Health Perspectives, among others, as well as Canadian Chemical News, which he edited for four years.

E-mail: tlougheed@wfsj.org.

Martin W. Bauer read Psychology and Economic History (Bern, Zurich, London), and is Professor of Social Psychology (London School of Economics and Political Science, LSE). He was Editor-in-Chief of Public Understanding of Science (2009-2016), and he investigates 'common sense' in comparative perspective and its relationship to global techno-scientific developments. Recent books: (2015) Atoms, Bytes \& Genes - Public Resistance and Techno-Scientific Responses, NY, Routledge; (2019) The Cultural Authority of Science - comparing across Europe, Asia, Africa, and the Americas, London, Routledge; and (2021) Psychology of Social Influence - Modes and Modalities of Shifting Common Sense, Cambridge, CUP. E-mail: M.Bauer@lse.ac.uk.

\section{How to cite}

Massarani, L., Neves, L. F. F., Entradas, M., Lougheed, T., Bauer, M. W. (2021). 'Perceptions of the impact of the COVID-19 pandemic on the work of science journalists: global perspectives'. JCOM 20 (07), A06. https://doi.org/10.22323/2.20070206. 